DOI: 10.21625/resourceedings.v2i1.740

\title{
Applications of Nanomaterials in Architectural Design
}

\author{
Hala Abdelmoez Mohamed ${ }^{1}$ \\ ${ }^{1}$ Lecturer \& Head of Architecture Dept. at The Higher Technological Institute 6th of October
}

\begin{abstract}
Recently Nanomaterials and Nanotechnologies play a major role in architectural design; building materials combined with nanotechnology became smaller, lighter, and work better than what is possible with conventional materials.

Many distinguish applications have been established in architecture and construction industry, for example improving the performance of traditional building materials, both structural materials such as (concrete, steel and wood) and nonstructural materials such as (glass, coating, and Air purification).
\end{abstract}

Presenting number of study cases for Nonstructural Nanomaterial applications.

(C) 2020 The Authors. Published by IEREK press. This is an open access article under the CC BY license (https://creativecommons.org/licenses/by/4.0/).

\section{Keywords}

Nanotechnology, Nanomaterials, Nanoarchitecture, Smart materials, Sustainable Nanomaterials, Green nanotechnology.;

\section{Introduction}

Nanotechnology is one of the most active research areas in both fields novel science and useful applications which have gradually established great success in the past two decades. Recent researches on nanomaterial and nanotechnologies foxed on the potential use of these materials in various fields such as medicine, construction, automobile industry, energy, telecommunications and informatics. This is due to the special characteristics of materials at the nano scale. It has been demonstrated that nanotechnology generated products have many unique characteristics, and can significantly fix many field problems (Khandve, 2014).

Nanotechnology add changes to building material properties that can improve the current construction materials to be lighter, stronger structural composites, low maintenance coatings, better cementations materials, and thermal insulation. Because size of the particles is a critical factor, the material properties significantly differ at the Nano scale from the larger scales.

\section{Nanotechnology and Nanometer}

First there are some terms we need to understand

\subsection{Nanotechnology}

Nanotechnology is the design, characterization, production and application of forms, mechanisms and systems through controlled manipulation of shapes and dimensions at Nano scale that produces forms and systems with at least one improved or new property (Parthenopoulou and Malindretosa, 2016). 


\subsection{Nanometer}

A nanometer $(\mathrm{nm})$ is one billionth of a meter. This size scale can be difficult to grasp and is perhaps best understood by analogy to common materials. A nanometer is about 100,000 times smaller than either the diameter of a human hair (Fig. 1) or the thickness of a sheet of paper. A red blood cell is approximately $5000 \mathrm{~nm}$ in size (Sellers, et al, 2009).

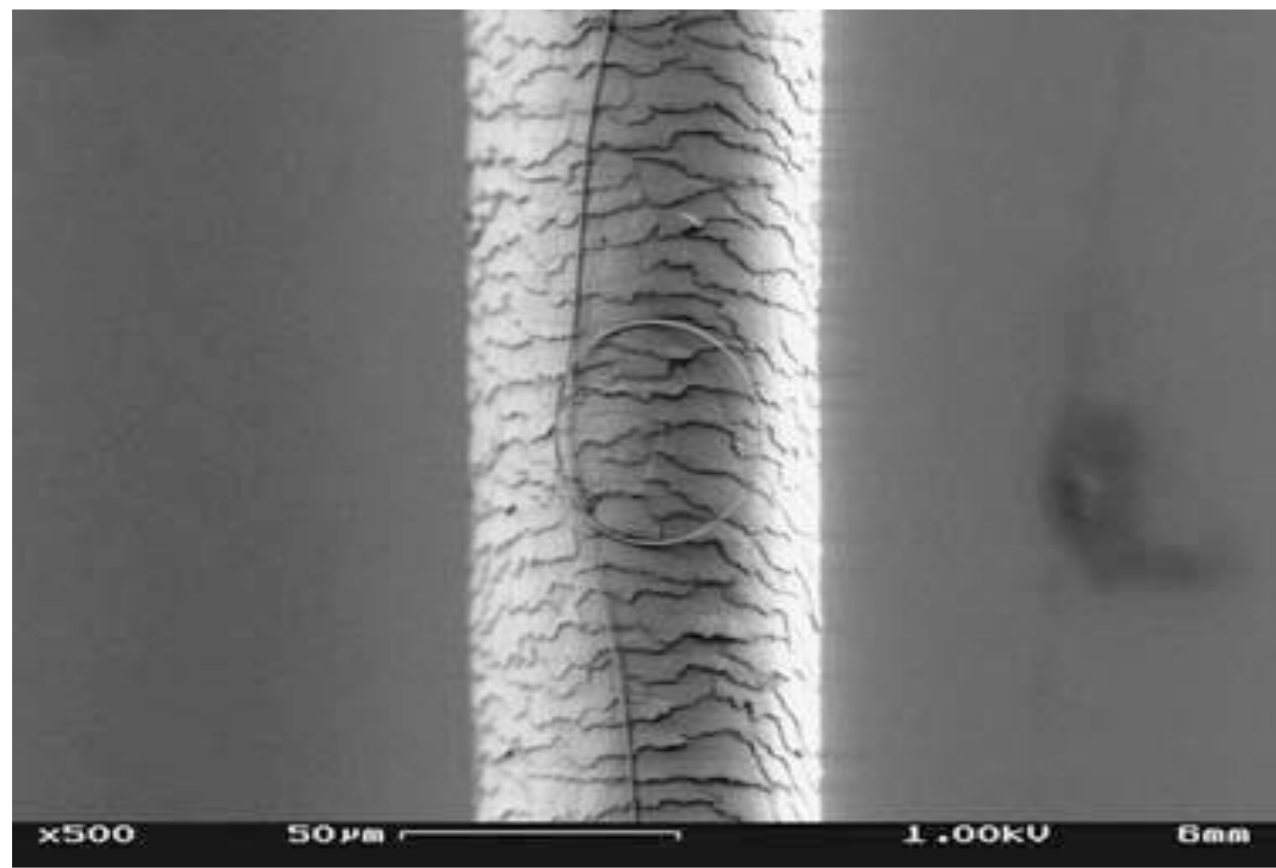

Fig.1: Micrograph of a nanowire curled into a loop in front of a strand of human hair (Sellers, et al, 2009)

\section{Nano-Architecture}

$($ Nanotechnology + Architecture $=$ Nano-Architecture $)$

Nano-Architecture combines nanotechnology with architecture and its versatile effects. It is concerned with the influences of nanotechnology applications in architecture and interior design. Nano-Architecture will allow design solutions to interact better with the human senses (Anous, 2014).

Table 1. Applications of nanotechnology in architecture (Ezel, 2014)

\section{Nanomaterials in Architecture}

\begin{tabular}{cc}
\hline Structural materials & Non-structural materials \\
Concrete & Glass \\
Steel & Coating \\
Wood & Insulation \\
& Filtration, Air purification \\
\hline
\end{tabular}

\section{Nanomaterials Applications in Architecture for Structural Materials}

Structural materials are of great importance in a building, since they determine the durability, longevity and also sustainability of the structure. A structural material's strength/weight ratio is also important, because stronger and lighter materials can carry greater loads per unit of material (Ezel, 2014).

Those materials such as concrete, steel and wood. 


\subsection{Nanomaterials in Concrete}

Nanotechnology is leading to new cements, concretes, admixtures (concrete performance enhancing additives) low energy cements, Nano composites, and improved particle packing. The addition of nanoparticles, for example, can improve concrete's durability through physical and chemical interactions such as pour filling. (Fouad, 2012).

\subsubsection{Self-healing concrete}

When self-healing concrete cracks, embedded microcapsules rupture and release a healing agent into the damaged region through capillary action (Fig. 2). The released healing agent contacts an embedded catalyst, polymerizing to bond the crack face closed. In fracture tests, self-healing composites recovered as much as $75 \%$ of their original strength. They could increase the life of structural components by as much as two or three times (Fouad, 2012) .

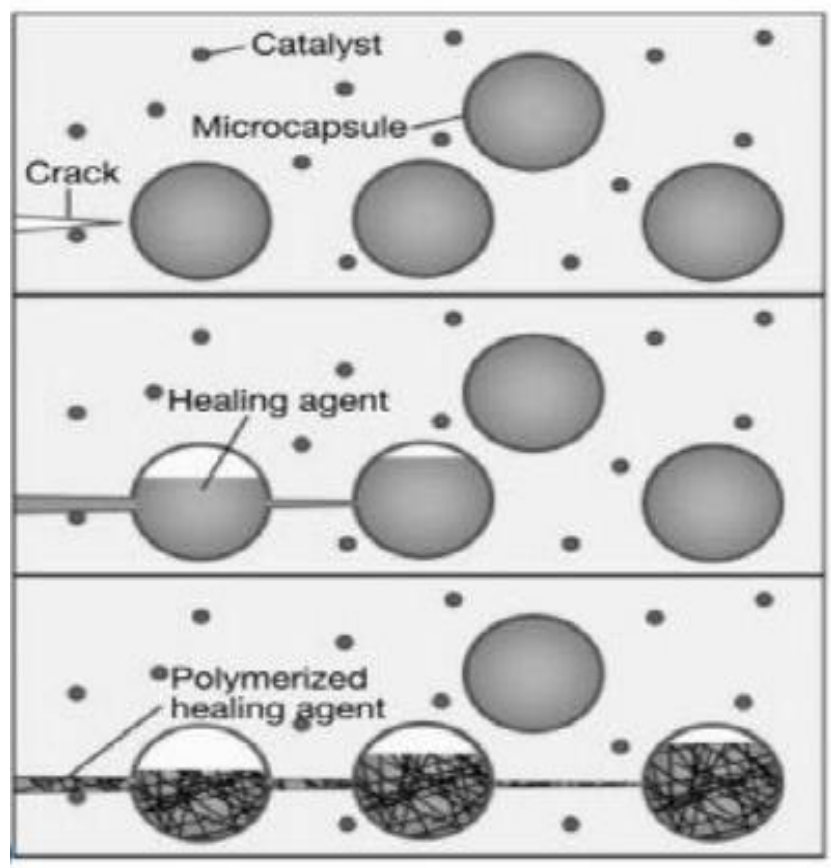

Fig.2: Self-healing process in concrete (Fouad, 2012).

\subsubsection{Concrete passing of light}

Today, Concrete passing of light is proposed as a new building material with high usability. This material is a combination of optical fibers and concrete particles and can be used as building blocks or prefabricated panels (Fig.3a, 3-b). Because of their small size of fiber they mixed with Concrete and form a combination of granulated material; so, the result is not just a combination of two materials, glass and concrete but also, is a third new material that in terms of the internal structure and external surfaces of complete homogeneity(www.seminarsonly.com,2018).

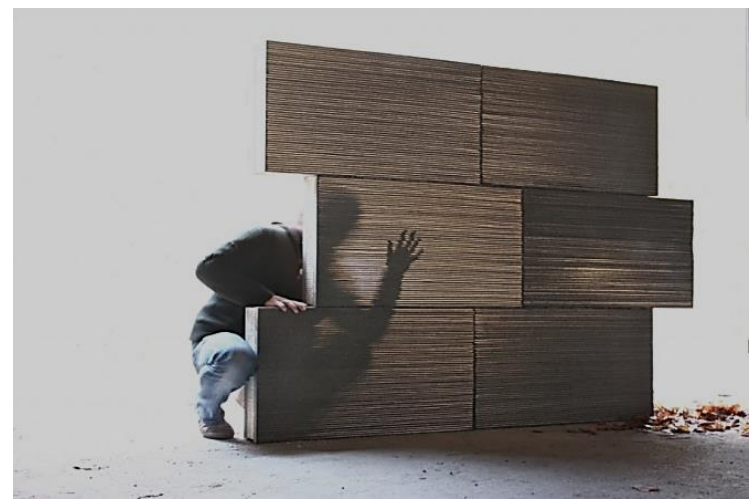

Fig. 3a. Transparent concrete wall (std1.bebee.com)

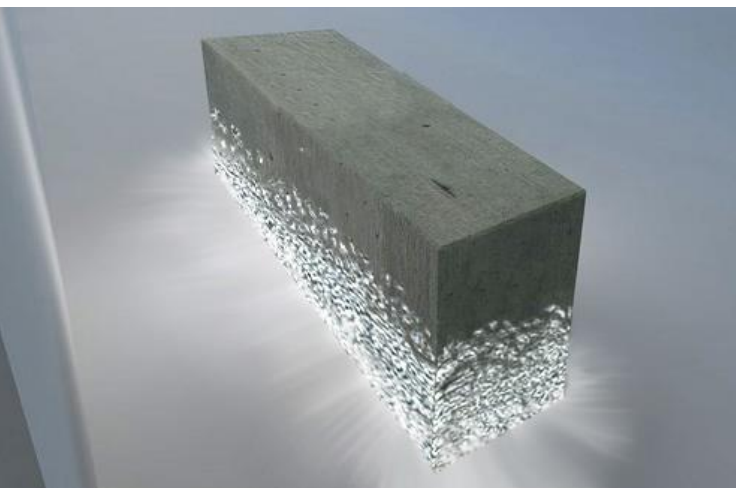

Fig. 3b. Transparent concrete block (cdn.home-designing.com) 
Another concrete can be noted as lightweight and ultra-light concrete. Water-proof concrete is a new material that has been invented in recent decades. Zycosil is a waterproof concrete and building materials with trade name of Zycosil which is new generation of nanotechnology that the concrete resist against the heat and UV and corrosion. These particles have been made with very low penetration (Kazempour, 2016).

\subsection{Nanomaterials in Steel}

Steel's high strength/weight ratio and combination of compressive and tensile strength make it the material of choice for tall buildings. But it can be weakened by corrosion and is extremely heavy. Corrosion can be inhibited; however, using application of nanotechnology can solve these problems (Elvin,2007).

The steel products manufactured with nanotechnology such as:

\subsubsection{Sandvik NanoflexTM Stainless steel}

Sandvik Nanoflex ${ }^{\mathrm{TM}}$ is new stainless steel with ultra-high strength, good formability, and a good surface finish developed by Sandvik Nanoflex Materials Technology. Due to its high performance, Sandvik Nanoflex ${ }^{\mathrm{TM}}$ is suitable to be applied wherever required lightweight and rigid designs. For certain applications, the components could be even thinner and lighter than that; which been made from aluminum and titanium due to its ultra-high strength and modulus of elasticity. Its good corrosion and wear resistance can keep life-cycle costs low. Attractive or wear resistant surfaces can be achieved by various treatments (Sandvik Nanoflex Materials Technology). (Gao,2008).

\subsubsection{MMFX2 Steel}

For the construction of bridges desirable properties like, requirement of less steel, higher yield strength, longer lasting, high corrosion resistance, lower maintenance, labor, production, installation costs when compared to conventional carbon steel, keeping a check of growth of micro (Das , and Mitra,2014).

\subsubsection{Nanomaterials in Wood}

Wood is composed of nanotubes or "Nano fibrils". Lignocellulose surfaces at the Nano-scale could open new opportunities for such things as self-sterilizing surfaces, internal self-repair, highly water repellent coatings incorporating silica and alumina nanoparticles and hydrophobic polymers are proper to be used for wood (Vigneshkumar,2014).

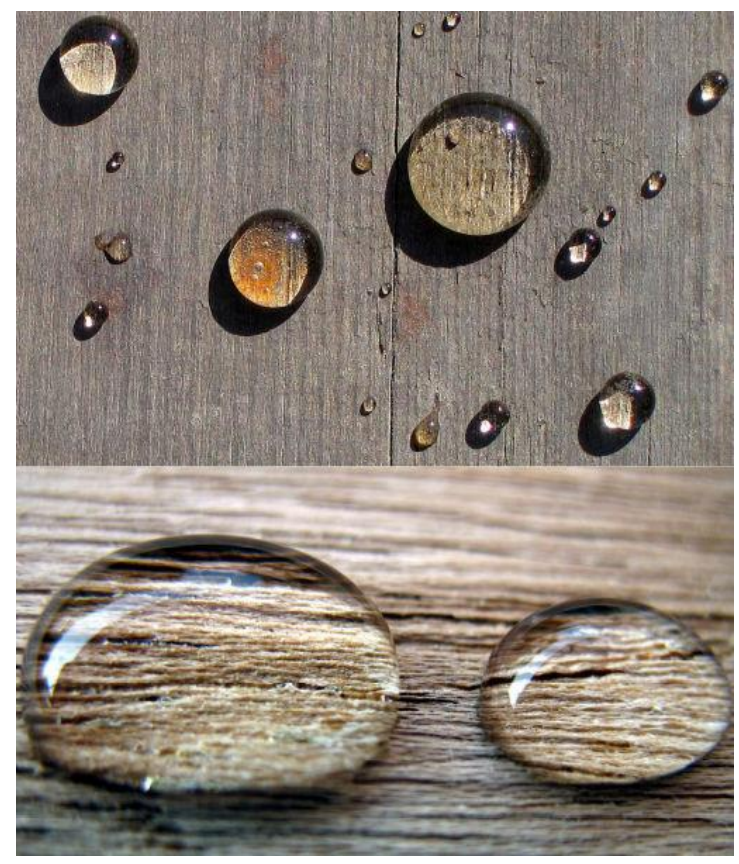

Fig.4 waterbroof wood (ultrahydrophobiccoating.com) 


\section{Nanomaterials Applications in Architecture for Nonstructural Materials}

Nonstructural materials contain any building material not related to the building structural system such as glass, coating materials and isolating materials.

\subsection{Nanomaterial in glass}

Controlling light and heat entering through building glazing is a major sustainability issue. Nanotechnology offers four different strategic solutions to block light and heat coming in through windows.

a) Thin film coatings are being developed which are spectrally sensitive surface applications for window glass. These have the potential to filter out unwanted infrared frequencies of light reducing the heat gain in buildings; however, these are effectively a passive solution.

b) As an active solution thermo-chromic technologies are being studied which react to temperature and provide thermal insulation to give protection from heating whilst maintaining adequate lighting.

c) A similar outcome by a different process, involves photo-chromic technologies which are being studied to react to changes in light intensity by increasing absorption.

d) Electro-chromic coatings are being developed that react to changes in applied voltage by using a tungsten oxide layer; thereby becoming more opaque at the touch of a button (Fig. 5). All these applications are intended to reduce energy used in cooling buildings and could make a major dent in the huge amounts of energy used in the built environment (Mann, 2006)

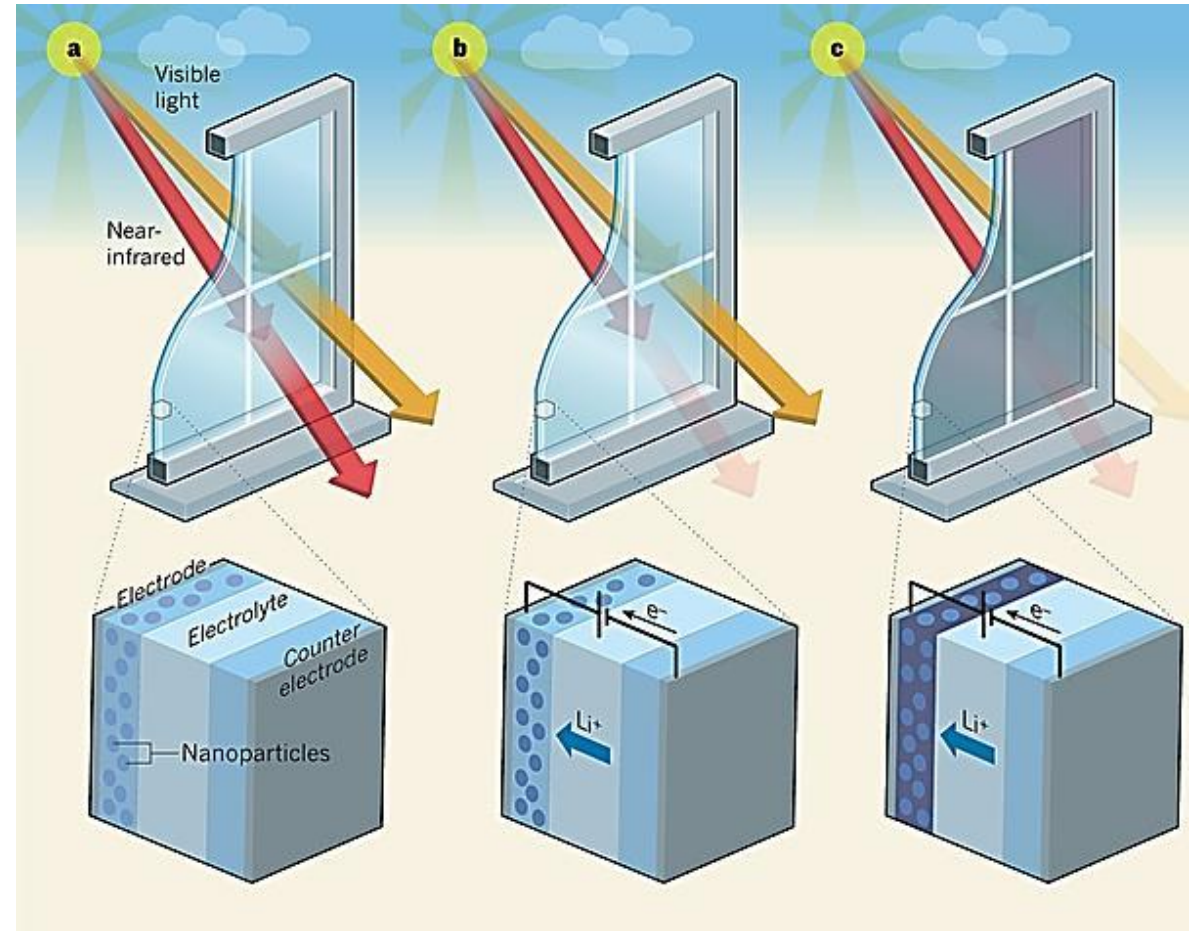

Fig. 5 EC windows with Nanotechnology (sustainingourworld.com)

\subsection{Nanomaterials in coating materials}

\subsubsection{Self-cleaning "Lotus-Effect"}

Lotus leaves exhibit a microscopically rough water-repellent (hydrophobic) surface, which is covered with tiny knobbles or spikes so that there is little contact surface for water to settle on Artificial lotus surfaces, created with the help of nanotechnology, The Lotus-Effect is most well suited for surfaces that are regularly exposed to sufficient quantities of water, e.g. rainwater. The Lotus- Effect drastically reduces the cleaning requirement and surfaces that are regularly exposed to water remain clean. The advantages are self-evident: a cleaner appearance and considerably reduced maintenance demands (Mohamed, 2015). 
Mohamed/ Proceedings of Science and Technology

Table 2.Strucksbarg housing

\begin{tabular}{|c|c|}
\hline Architect & Renner Hainke Wirth Architekten \\
\hline Country & Hamburg, Germany \\
\hline Product & Lotusan, self-cleaning paint (Lotus-Effect) \\
\hline Manufacturer & STO \\
\hline Completion & 2007 \\
\hline Area & $3,685 \mathrm{~m} 2$ facade area \\
\hline
\end{tabular}

As with earlier renovation projects; the architects chose to use self-cleaning façade coatings for their renovation of a 1970s housing estate. The estate consists of a high-rise block as well as a number of multi-storied terraced housing blocks. The renovated elevations are cladded in a composite thermal insulation system with a pigmented render coating in light beige and red.

As part of the redesign, window recesses were given color highlights, the house entrances were made more prominent, wired glazing was replaced with transparent clear glass, bathrooms were given windows and the undersides of balconies were painted in color. The differentiated coloring of the new facades is most apparent. Warm colors in a palette between yellow and red lend the entire estate a pleasant and unified appearance. As regards the self-cleaning function, Hamburg proves to be an ideal location as there is no lack of rain (Leydecker,2008)

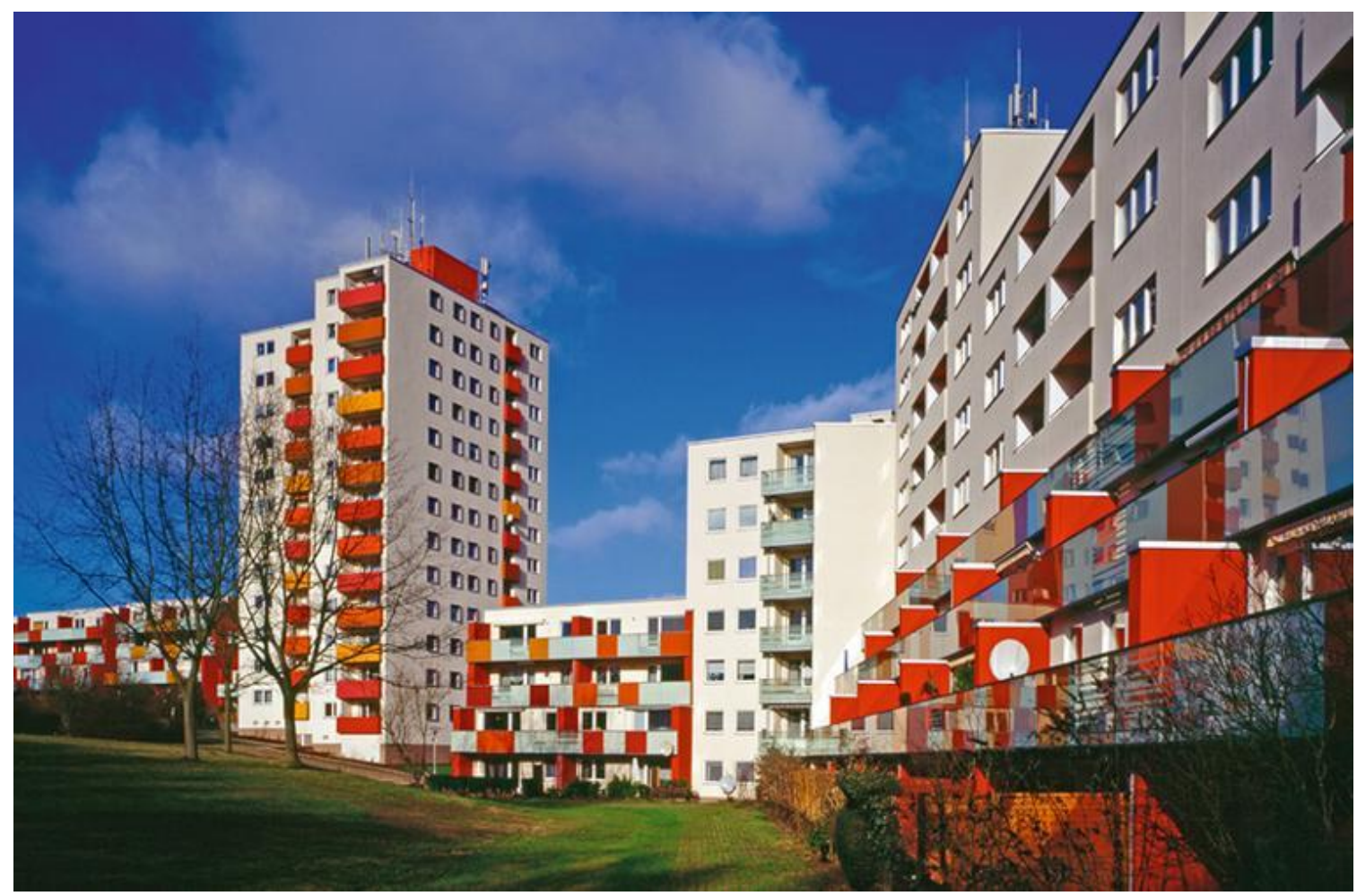

Fig.6 The Exterior of Struckbarg Housing (www.detail.de)

\subsubsection{Self-cleaning Photo-catalysis}

Photo-catalytic coatings containing titanium dioxide (TiO2) nanoparticles; these nanoparticles initiate photocatalysis, a process by which dirt is broken down by exposure to the sun's ultraviolet rays and washed away by rain. VOCs (Volatile Organic Compounds) are oxidized into carbon dioxide and water. Today's self-cleaning surfaces are made by applying a thin Nano-coating film, painting a Nano-coating on, or integrating nanoparticles into the surface layer of a substrate material (Mohamed, 2015). 
Mohamed/ Proceedings of Science and Technology

Table 3.Hyatt Regency Garden Chapel

\begin{tabular}{|c|c|}
\hline Architect & Obayashi Corporation \\
\hline Country & Osaka, Japan \\
\hline Product & Sky Clear Coat fabric/TiO^ photocatalytic self-cleaning \\
\hline Manufacturer & Taiyo Kogyo Corporation \\
\hline Completion & 2001 \\
\hline Area & $50 \mathrm{~m} 2$ \\
\hline
\end{tabular}

A small covered chapel sits atop the expansive roof garden of this hotel, and is used for Christian wedding ceremonies. By day, its pure white membrane covering in combination with the green of the well-kept lawns creates a fresh contrast; at night it becomes a bright glowing sculpture. In its function as a wedding chapel it is essential that it always appears clean and neat as the classic color of Christian weddings is white. Without its photo-catalytic self-cleaning surface, the white of the membrane would not have lasted long without having to be cleaned regularly or even replaced at intervals (Leydecker,2008).

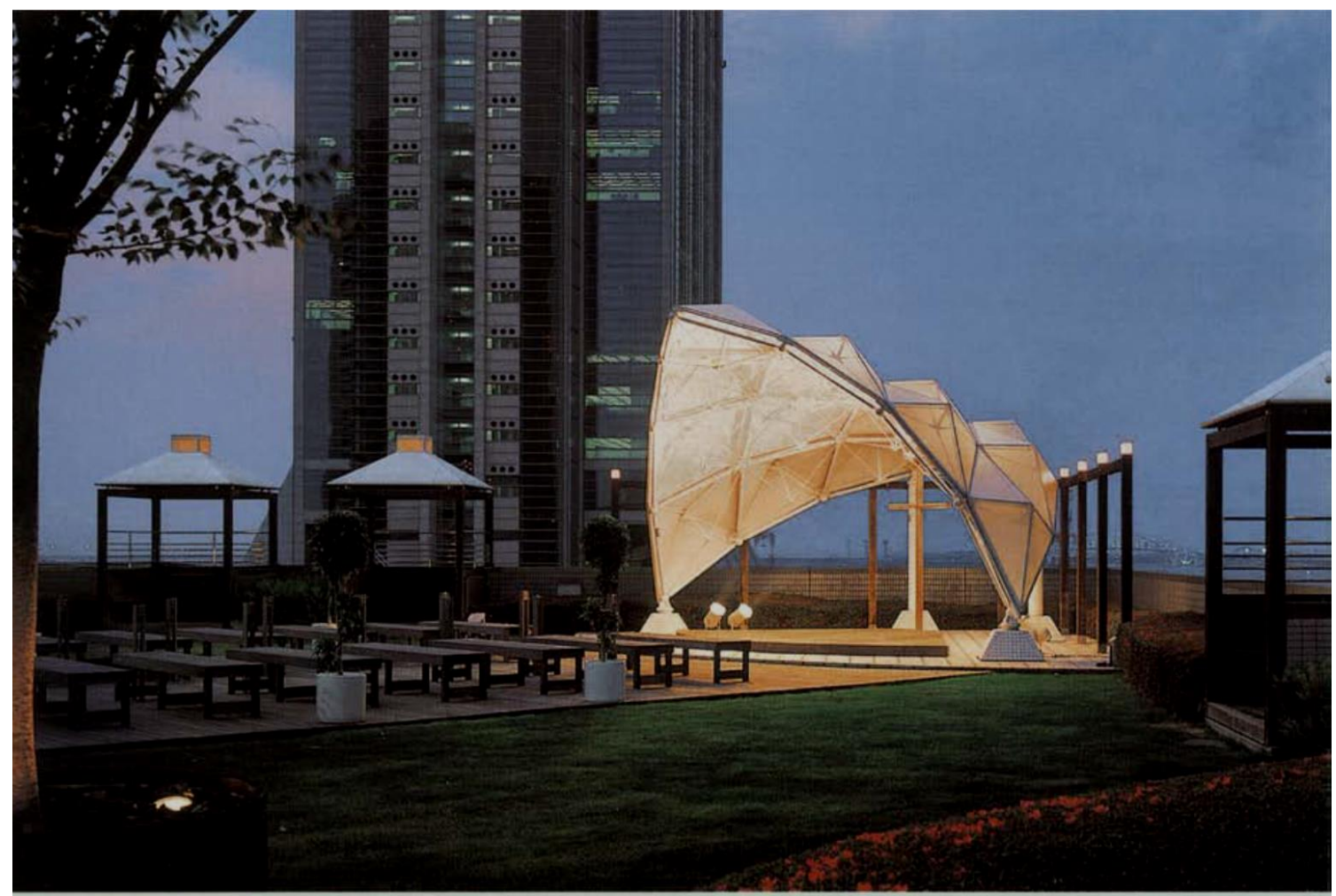

Fig.7 Exterior of Hyatt Regency Garden Chapel (Leydecker,2008)

\subsubsection{Easy-to-clean (ETC)}

It is a: confused with other self-cleaning functions, such as the lotus-effect, easy-to-clean surfaces are smooth rather than rough. These surfaces have a lower force of surface attraction due to a decrease in their surface energy. As a result it reduces surface adhesion, this results in water to be repelled and in forming droplets and running off. Easyto-clean surfaces are therefore hydrophobic, water-repellent and often also oil-repellent, making them well suited for use in bathrooms (Mohamed, 2015).

The easy-to-clean function of surfaces is also often confused with other photo-catalytic self-cleaning functions. The primary difference here is that easy-to-clean surface coatings do not require UV light to operate, and their hydrophobic surface properties cause water to run off in droplets rather than forming a thin film of water. 
Mohamed/ Proceedings of Science and Technology

Table 4.Science to Business Center Nanotronics \& Bio

\begin{tabular}{|c|c|}
\hline Architect & Henn Architekten \\
\hline Country & Munich, Germany \\
\hline Product & ccflex, nanoceramic wall covering \\
\hline Manufacturer & At the time of construction Degussa, today Evonik \\
\hline Completion & 2005 \\
\hline
\end{tabular}

The research Centre was conceived and built for Degussa, with its transparent façade, clear forms and material and color concept, the architecture embodies the company philosophy: the transfer of know-how from science to business. Degussa benefits from being able to use their in-house products: various parts of the interior feature a particularly robust Nano-ceramic wall covering. It is flexible, impact-resistant and is vapor permeable whilst at the same time water-repellent. It can be applied similar to normal wallpaper and is available in rolls.

Beyond conventional applications, it can also be used in areas where conventional wallpaper would be inappropriate, for instance as a replacement for wall tiles in toilet areas. The water-repellent surface, together with a water-repellent adhesive to protect the joins, means that this product can be used in all manner of wet areas. In this respect it compares favorably with wall tiles. Thanks to a slightly mottled coloring the joins are practically invisible, giving the impression of a homogeneous uninterrupted surface (Leydecker, 2008).

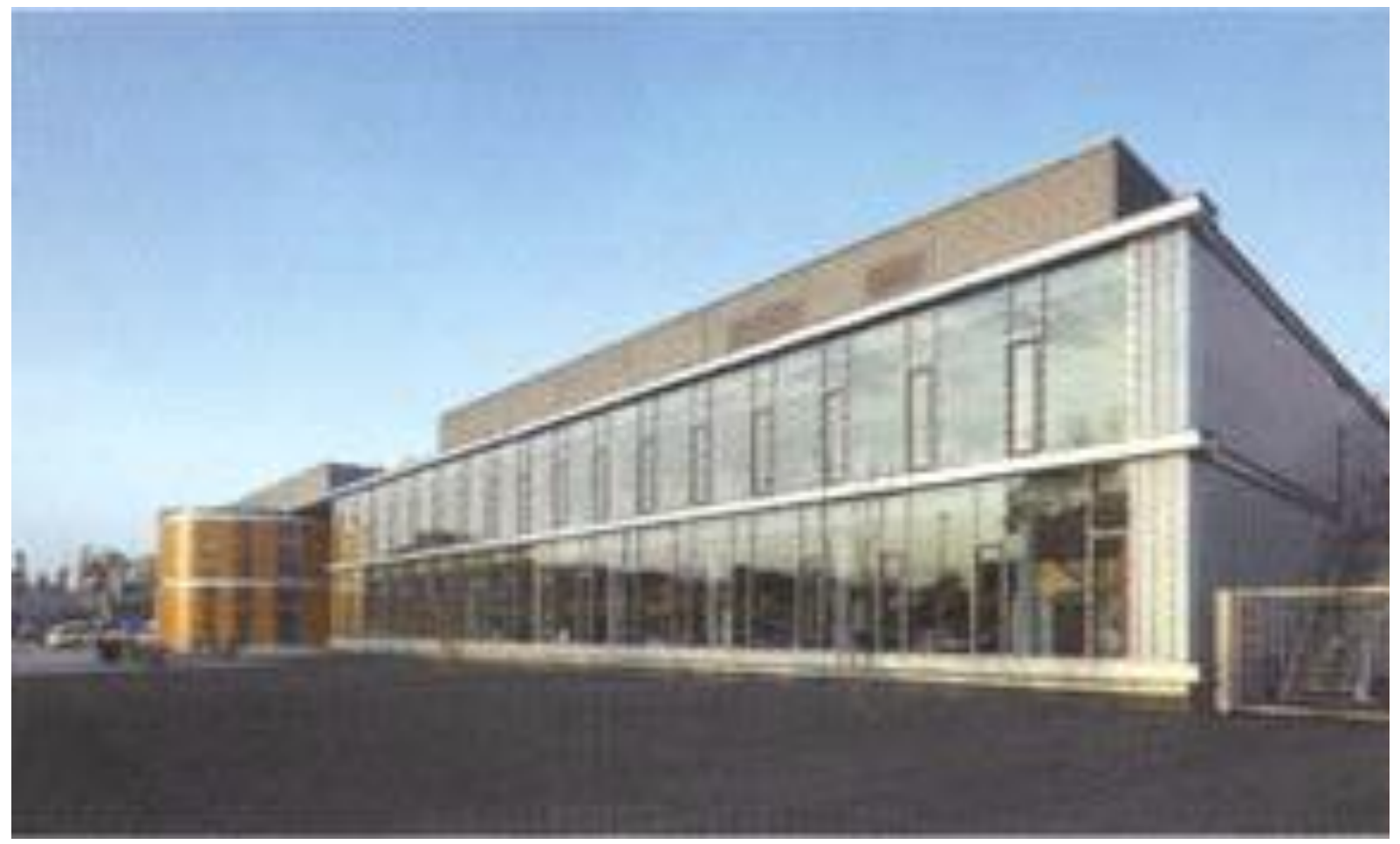

Fig.8 The Exterior of Science to Business Center Nanotronics \& Bio. (Leydecker, 2008)

\subsubsection{Nanomaterials for Air-purifying}

Though not able to completely purify air, the use of nanomaterial makes it possible to improve the quality of air. It enables unpleasant odors and pollutants to be eradicated. Healthy air is a fundamental and ever more important resource that at the same time is becoming ever more precious.

Legislation was initially introduced to reduce the level of outdoor air pollution; the need to improve indoor air quality followed later. The air-purifying properties of nanomaterial are beneficial in both cases and play an important role both for indoor as well as increasingly for outdoor environments (Atwa et al., 2015). 
Table 5.Atelier and villa for a calligrapher

\begin{tabular}{|c|c|}
\hline Architect & Kazuyasu Kochi, Kochi Architect's Studio \\
\hline Country & Tokyo, Japan \\
\hline Product & Moiss, air-purifying building board \\
\hline Manufacturer & Mitsubishi \\
\hline Completion & 2004 \\
\hline Area & $62 \mathrm{~m}^{2}$ \\
\hline
\end{tabular}

This unusual weekend house and calligraphy atelier has two stories and a roof terrace. Although located in the countryside with fresh air all around, the indoor air atmosphere is less than ideal due to its sporadic use as a weekend house, as it is aired only irregularly. By using unvarnished wood and air-purifying building boards that eliminate airborne contaminants, the architect was able to reduce the problem of poor air.

The building boards are vapor permeable, absorbing and releasing moisture from and back into the air, in the process cleaning pollutants and odors from the air by breaking them down into their constituent parts. In addition, the building boards can be safely disposed of after the end of their useful lifetime (Leydecker, 2008).

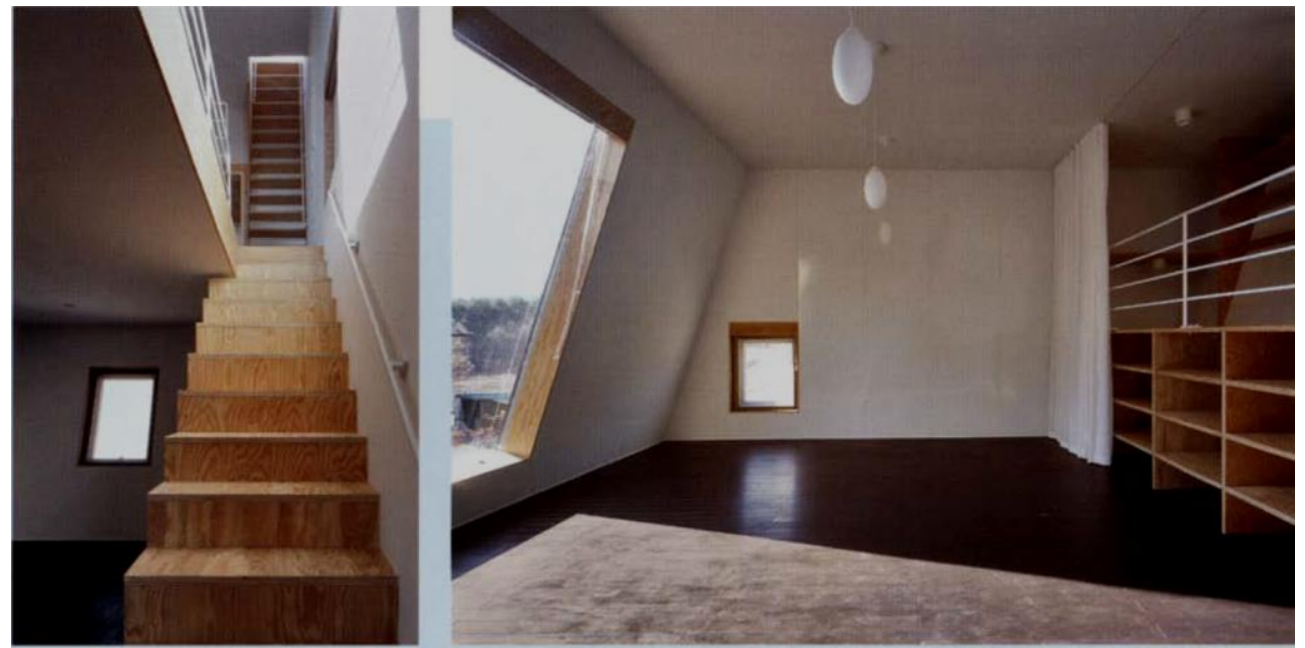

Fig.9 Interior of the Atelier (Leydecker, 2008)

\section{Conclusion}

1- Nanotechnology is one of the most active research areas in both fields novel science and useful applications which have gradually established great success in the past two decades.

2- Nanotechnology add changes to building material properties that can improve the current construction materials to be lighter, stronger structural composites, low maintenance coatings, better cementations materials, and thermal insulation.

3- Nano-Architecture combines nanotechnology with architecture and its versatile effects. It is concerned with the influences of nanotechnology applications in architecture and interior design.

4- There are Nanomaterial Applications in Architecture for Structural Materials; those materials such as concrete, steel and wood.

5- Nanomaterials in Concrete applications verstile from Self-healing concrete, to Concreat passing of light.

6- Nanomaterials in Steel applications are such as Sandvik NanoflexTM Stainless steel which is a new stainless steel with ultra-high strength, good formability, and a good surface finish; and MMFX2 steel for the construction of bridges. 
7- Nanomaterials in Wood applications cosidring Lignocellulose surfaces at the Nano-scale could open new opportunities for such things as self-sterilizing surfaces, internal self-repair, highly water repellent coatings.

8- There are Nanomaterial applications in Architecture for Nonstructural materials such as glass, coating materials and isolating materials.

9- Nanomaterial in Glass applications vary from Thin film coating, Thermo-chromic technologies, to Electrochromic coatings.

10-Nanomaterials in coating materials applications are numerous like :

- Self-cleaning "Lotus-Effect" applied in Strucksbarg housing at Germany.

- Self-cleaning Photo-catalysis applied in Hyatt Regency Garden Chapel at Japan.

- Easy-to-clean (ETC) applied in Science to Business Center Nanotronics \& Bio at Germany.

- Nanomaterials for Air-purifying applied an Atelier and villa for a calligrapher at Japan.

11-Nano-Architecture gives us the opportunity to design smart green buildings efficiontly with long life materials.

\section{References}

Anous, I. (2014). Nanomaterials and Their Applications in Interior Design, American International. Journal of Research in Humanities, Arts and Social Sciences, 7(1), 16-17.

Atwa, M., Al-Kattan, A., \& Elwan, A. (2015). Towards Nano Architecture: Nanomaterial in Architecture-A review of functions and applications. International Journal of Recent Scientific Research, 6(4), 3551-3564.

Das, B. B., \& Mitra, A. (2014). Nanomaterials for construction engineering-A review. International Journal of Materials, Mechanics and Manufacturing, 2(1), 41-46.

Elvin, G. (2007, May). Building green with nanotechnology. In Proceedings of NSTI Nanotechnology Conference and Trade Show-NSTI Nanotech (pp. 20-24).

Fouad, F. F. (2012). NanoArchirecture and Sustainability. [Master Thesis, Alexandria University]..

Ge, Z., \& Gao, Z. (2008). Applications of nanotechnology and nanomaterials in construction. First Inter. Confer. Construc. Develop. Countries, $235-240$.

Kazempour, A. (2016). The impact of Nanotechnology in reinforced structures the structure of Concrete and steel. Journal of Current Research in Science, (1), 421.

Khandve, P. (2014). Nanotechnology for building material. International Journal of Basic and Applied Research, 4, $146-151$.

Leydecker, S. (2008). Nano materials: in architecture, interior architecture and design. Springer Science \& Business Media.

Mann, S. (2006). Nanotechnology and Construction. Nanoforum report.

Mohamed, A. S. Y. (2015, April). Nano-Innovation in Construction, A New Era of Sustainability. In International Conference on Environment and Civil Engineering (Vol. April, pp. 97-100-108). Pattaya-Thailand.

Parthenopoulou, N. K., \& Malindretos, M. (2016). The Use of Innovative Materials in Innovative Architectural Applications. Combining Forces for High Performance Structures. Materials Today: Proceedings, 3(3), 898-912.

Sellers, K., Mackay, C., Bergeson, L. L., Clough, S. R., Hoyt, M., Chen, J., ... \& Hamblen, J. (2009). Nanotechnology and the Environment. CRC press.

Sev, A., \& Ezel, M. (2014). Nanotechnology innovations for the sustainable buildings of the future. World Academy of Science, Engineering and Technology International Journal of Civil, Environmental, Structural, Construction and Architectural Engineering, 8(8), 886-896.

Transparent Concrete | Seminar Report, PPT, PDF for Civil Engineering. Retrieved 15 October 2020, from https://www.seminarsonly.com/Civil_Engineering/transparent-concrete.php

Vigneshkumar, C. (2014). Study on nanomaterials and application of nanotechnology and its impacts in construction. Discovery, $23,8-12$.

(n.d.) Retrieved from cdn.home-designing.com/wp-content/uploads/2015/03/concrete-ideas-600x321.png

(n.d.) Retrieved from https://std1.bebee.com/br/pb/89107/72f8185c/900

(n.d.) Retrieved from https://sustainingourworld.com/wp-content/uploads/2015/10/EC-windows-with-nanotechnology.jpg

(n.d.) Retrieved from https://ultrahydrophobiccoating.com/wp-content/uploads/2016/08/waterproof-wood-water-resistant-cardboard-cracks.jpg

(n.d.) Retrieved from https://www.detail.de/uploads/pics/135_762_500.jpg

(n.d.) Retrieved from https://www.hyatt.com/en-US/hotel/japan/hyatt-regency-osaka/osaka/photosreviews 